\title{
MicroRNA-145 is a potential prognostic factor of scirrhous type gastric cancer
}

\author{
YUTAKA NAITO $^{1}$, KYOHEI YASUNO ${ }^{2}$, HIROKO TAGAWA ${ }^{2}$, NAOYA SAKAMOTO $^{1}$, NAOHIDE OUE ${ }^{1}$, \\ MASAKAZU YASHIRO $^{3}$, KAZUHIRO SENTANI ${ }^{1}$, KEISUKE GOTO $^{1}$, SHUNSUKE SHINMEI $^{1}$, \\ HTOO ZARNI OO $^{1}$, KAZUYOSHI YANAGIHARA ${ }^{4}$, KOSEI HIRAKAWA ${ }^{3}$ and WATARU YASUI ${ }^{1}$ \\ ${ }^{1}$ Department of Molecular Pathology, Hiroshima University Institute of Biomedical and Health Sciences, Minami-ku; \\ ${ }^{2}$ Faculty of Medicine, Hiroshima University, Minami-ku, Hiroshima 734-8551; ${ }^{3}$ Department of Surgical Oncology, \\ Osaka City University Graduate School of Medicine, Abeno-ku, Osaka 545-8585; ${ }^{4}$ Division of Translational Research, \\ Exploratory Oncology and Clinical Trial Center, National Cancer Center, Kashiwa, Chiba 277-8577, Japan
}

Received April 17, 2014; Accepted June 13, 2014

DOI: $10.3892 /$ or.2014.3333

\begin{abstract}
Gastric cancer (GC) is one of the most common malignancies worldwide. In particular, scirrhous type GC is highly metastatic and is characterized clinically by rapid disease progression and poor prognosis. MicroRNAs (miRNAs) play crucial roles in cancer development and progression. We previously demonstrated by microarray analysis that microRNA-145 (miR-145) is one of the more highly expressed miRNAs in scirrhous type GC vs. non-scirrhous types of GC. In the present study, we investigated the role of miR-145 in scirrhous type GC. The expression levels of miR-145 assessed by quantitative RT-PCR were higher in scirrhous type GC tissue samples than in non-scirrhous type GC and corresponding normal tissues. GC patients with high miR-145 expression were at a more advanced tumor stage $(\mathrm{P}=0.0156)$ and had more scirrhous type histology $(\mathrm{P}=0.0054)$ than those with low miR-145 expression. Furthermore, miR-145 expression was significantly associated with poor prognosis in GC patients $(\mathrm{P}=0.0438)$. miR-145 expression was localized in stromal fibroblasts of scirrhous type GC but not in cancer cells. miR-145 was induced by treatment by transforming growth factor- $\beta$, and it enhanced the expression of $\alpha$-smooth muscle actin, a marker of myofibroblasts, in both normal gastric fibroblasts and cancer-associated fibroblasts. These data suggest that miR-145 may contribute to the progression of scirrhous type GC by regulating activation of peri-tumoral fibroblasts.
\end{abstract}

Correspondence to: Professor Wataru Yasui, Department of Molecular Pathology, Hiroshima University Institute of Biomedical and Health Sciences, 1-2-3 Kasumi, Minami-ku, Hiroshima 734-8551, Japan

E-mail: wyasui@hiroshima-u.ac.jp

Key words: $\alpha$-smooth muscle actin, fibroblast, microRNA-145, scirrhous type gastric cancer, transforming growth factor- $\beta$

\section{Introduction}

Gastric cancer (GC) is one of the most common malignancies worldwide. In particular, scirrhous type GC, composed mainly of a diffusely infiltrating type of poorly differentiated GC cells, forms a Borrmann type 4 lesion and is characterized by highly metastatic potential and rapid proliferation (1-3). Histologically, scirrhous type GC shows diffuse infiltration into the gastric wall with extreme stromal fibrosis (1-3). Transforming growth factor- $\beta$ (TGF- $\beta$ ), produced by cancer cells, activates stromal fibroblasts to produce various growth factors and stimulates collagen synthesis in scirrhous type GC (4-5). Growth-promoting factors from peri-tumoral fibroblasts also contribute to the progression of scirrhous type GC (3). Furthermore, increasing matrix rigidity may cause proliferation, and interstitial pressure created by fibrosis in the cancer stroma may interfere with drug delivery to cancer cells (6-9). Reflecting such characteristics, scirrhous type GC carries an extremely poor patient prognosis in comparison with other types of GC. Therefore, enhanced knowledge of the pathological and biological basis of scirrhous type GC may lead to improved diagnosis and treatment.

MicroRNAs (miRNAs) are small non-coding RNAs of 19-25 nucleotides in length that play important regulatory roles in post-transcriptional repression $(10,11)$. Through inhibition of target gene translation, miRNAs are involved in a wide range of cellular processes. Aberrant miRNA expression is found in a variety of cancers, suggesting novel roles as oncogenes or tumor-suppressor genes depending on the function of the target genes (12). Previously, we performed miRNA microarray analysis and identified several miRNAs that are significantly upregulated in scirrhous type GC (13). Among them, we reported that miR-143 regulates collagen type III expression to contribute to interstitial fibrosis and the poor prognosis of scirrhous type GC (13). It has been shown that miR-143 and miR-145 have a number of common features (14-16). It is well known that their expression is mediated by the same promoter and is induced by TGF- $\beta$ signaling (15), and they work cooperatively in the regulation of vascular 
smooth muscle cell differentiation (16). miR-145 was picked up as the second highest miRNA after miR-143 in our miRNA microarray analysis of scirrhous type GC (13). However, no reports, to our knowledge, have focused on the role of miR-145 in scirrhous type GC.

In the present study, we studied miR-145 expression in scirrhous type GC and the associations between miR-145 expression and clinicopathological factors including prognosis were investigated using quantitative RT-PCR (qRT-PCR) of formalin-fixed paraffin-embedded (FFPE) samples. Furthermore, we studied the function of miR-145 in stromal fibroblast in scirrhous type GC, particularly in the expression of $\alpha$-smooth muscle actin ( $\alpha$-SMA) by stromal fibroblasts.

\section{Materials and methods}

Tissue samples. In total, 138 primary gastric tumors and 30 corresponding non-neoplastic mucosa specimens were collected from patients diagnosed with GC. Patients were treated at Miyoshi Central Hospital or Hiroshima University Hospital. For miRNA microarray analysis, frozen GC tissue samples including 5 scirrhous type and 15 non-scirrhous type GCs were used. For qRT-PCR analysis, frozen GC tissue samples from 20 patients and archival FFPE tissue from 98 GC patients and 30 corresponding non-neoplastic mucosa samples were used. For immunohistochemical analysis and in situ hybridization, archival FFPE tissues from scirrhous type GC cases with high miR-145 expression, as measured by qRT-PCR, were used. Since written informed consent was not obtained, for strict privacy protection, identifying information for all samples was removed before analysis. This procedure was in accordance with the Ethical Guidelines for Human Genome/Gene Research of the Japanese Government.

Cell cultures. Nine cell lines derived from human GC were used. The TMK-1 cell line was established in our laboratory (17). The HSC-39, HSC-44PE and HSC-57 cell lines were established by one of the authors (Yanagihara et al) $(18,19)$. Four GC cell lines of the MKN series were kindly provided by Dr Toshimitsu Suzuki, and the KATO-III cell line was kindly provided by Dr Morimasa Sekiguchi. Four human normal gastric fibroblasts (NFs), NF-33, 34, 35 and 38, and four cancer-associated fibroblasts (CaFs), CaF-33, 34, 35 and 38, were established by one of the authors (M.Y.) and as previously described (13). NF-33, 38 and CaF-33, 38 were derived from scirrhous type GC patients, and NF-34, 35 and CaF-34, 35 were derived from patients with poorly differentiated gastric adenocarcinoma. CaFs had been established from the primary tumor site of GC tissue and NF cell lines from the 'normal' non-neoplastic counterpart (as matched pairs). These cell lines were maintained as previously described $(13,20,21)$.

$q R T-P C R$ and western blot analyses. Quantification of levels of $\alpha$-SMA and $\beta$-actin was performed using real-time fluorescence detection as previously described (22). $\alpha$-SMA primer sequences were: 5'-AGCCAAGCACTGTCAGGAATC-3' and 5'-GAGCCCAGAGCCATTGTCAC-3'. $\beta$-actin primer sequences were: 5'-TCACCGAGCGCGGCT-3' and 5'-TAAT GTCACGCACGATTTCCC-3'. qRT-PCR was performed with a SYBR-Green PCR Core Reagents kit (Applied Biosystems,
Foster City, CA, USA). For analysis of miR-145 and U6B expression levels from frozen samples, total RNA was extracted with a miRVana ${ }^{\mathrm{TM}}$ Isolation kit (Ambion, Austin, TX, USA) according to the manufacturer's instructions. Total RNA was isolated from FFPE tissue samples using the RecoverAll $^{\text {TM }}$ Total Nucleic Acid Isolation kit (Ambion) as previously described (23). Expression levels of miR-145 were normalized by RNU6B expression and calculated using the $\Delta \Delta \mathrm{Ct}$ method.

For western blot analysis, cells were lysed as previously described (24). The lysates $(30 \mu \mathrm{g})$ were solubilized in Laemmli sample buffer by boiling and then subjected to $12 \%$ SDS-polyacrylamide gel electrophoresis followed by electrotransfer onto a nitrocellulose membrane. The membrane was incubated with primary anti- $\alpha$-SMA antibody (Dako, Carpinteria, CA, USA) and anti- $\beta$-actin antibody (Santa Cruz Biotechnology, Santa Cruz, CA, USA). Immunocomplexes were visualized with an ECL Prime Western Blot Detection System (GE Healthcare, Little Chalfont, Buckinghamshire, UK).

Cell transfection and TGF- $\beta 1$ treatment. Transfection of cells was performed with Lipofectamine RNAiMAX Reagent (Invitrogen, Carlsbad, CA, USA) according to the manufacturer's instructions. Briefly, the cells were seeded at $50 \%$ confluence the day before transfection. Pre-miR-145, miR-145 inhibitor, and negative control miRNA (Ambion) were used for each transfection at a final concentration of $100 \mathrm{nM}$. Fibroblasts were incubated in DMEM containing $10 \mathrm{ng} / \mathrm{ml}$ TGF- $\beta 1$ (R\&D Systems, Minneapolis, MN, USA). After 0-48 h of incubation, collagen type III or miR-145 expression of fibroblasts was examined by qRT-PCR as described above.

Statistical analysis. The Mann-Whitney U test was used to calculate the significance of differences between two samples. Statistical differences between miRNA expression levels in GC samples and non-neoplastic mucosa samples were evaluated using the Wilcoxon matched pair test. The correlation between expression levels of miR-145 and clinicopathological parameters was analyzed with Fisher's exact test. A log-rank test and Kaplan-Meier plots were constructed for the miR-145 high and low groups, based on one third of the miR-145 expression level. Univariate and multivariate analyses of factors influencing survival were carried out using the Cox proportional hazards model. Parameters for multivariate analysis were selected by the stepwise method. A P-value of $<0.05$ was considered to indicate a statistically significant difference.

\section{Results}

Expression levels of miR-145 are greater in scirrhous type GC than in non-scirrhous type GC. Although miR-145 expression in GC has been discussed by several authors (25-28), there is no unified view of the altered expression of miR-145 in scirrhous type GC. To confirm miR-145 expression in GC tissue, we performed qRT-PCR in 20 frozen GC tissue samples. Scirrhous type GC cases showed significantly higher miR-145 expression, compared with non-scirrhous type GC cases (Fig. 1A). 

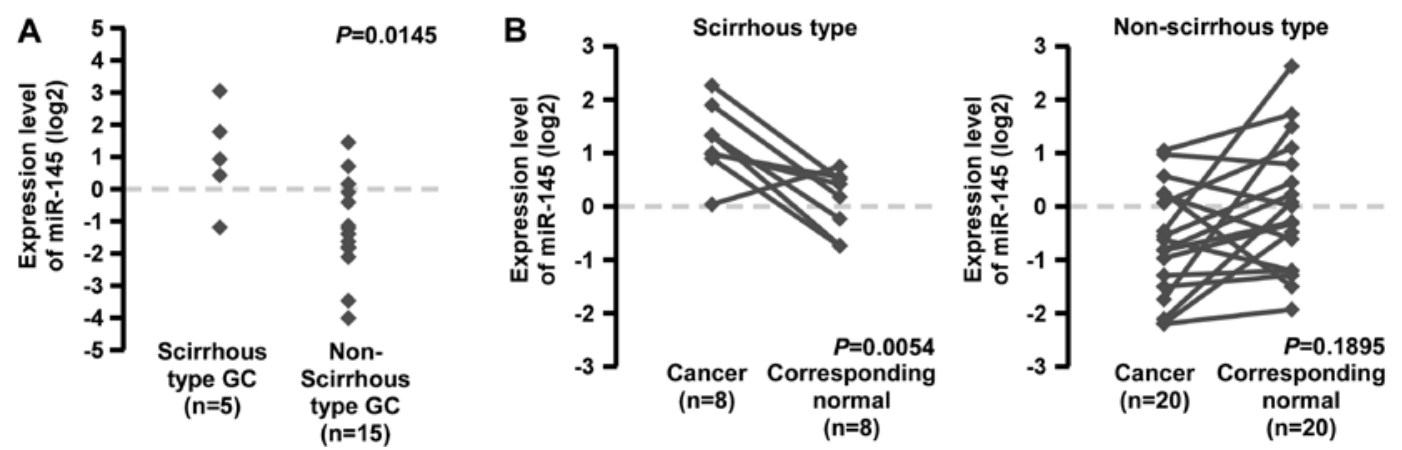

Figure 1. miR-145 expression in gastric cancer (GC) and non-neoplastic tissue. (A) Expression levels of miR-145 in GC tissue samples (n=20) were measured by quantitative RT-PCR (qRT-PCR) analysis. (B) miR-145 expression levels in formalin-fixed paraffin-embedded GC tissue samples and corresponding normal tissue samples derived from scirrhous type GC or non-scirrhous type GC as determined by qRT-PCR were compared. Bars and error bars indicate median and standard error (SE).
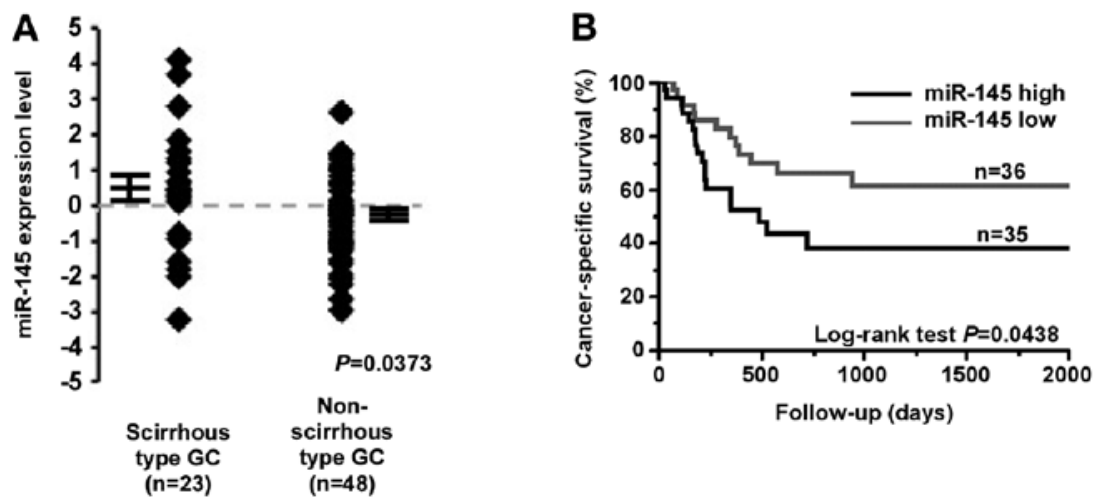

Figure 2. Relationship between miR-145 expression and patient prognosis. (A) Expression levels of miR-145 in formalin-fixed paraffin-embedded gastric cancer (GC) tissue samples ( $\mathrm{n}=71$ ) were measured by quantitative RT-PCR (qRT-PCR) analysis. (B) Cancer-specific survival of 71 patients with GC based on the expression levels of miR-145 was examined. The expression levels of miR-145 were divided into two groups, high and low expression of miR-145, based on one third of miR-145 expression level (cut-off line, median of miR-145 expression level in this group). Bars and error bars indicate median and standard error (SE).

It was reported that miR-145 expression is decreased in several tumor tissues relative to normal tissue (29-31). To assess miR-145 expression between tumor tissues and corresponding non-neoplastic tissues, we performed qRT-PCR of miR-145 using 28 FFPE GC tissue samples and corresponding normal gastric mucosa (Fig. 1B). Although miR-145 expression was significantly lower in non-scirrhous type GC tissues than in corresponding normal gastric mucosa, the expression levels in scirrhous type GC were sustained or higher than those in the corresponding normal gastric mucosa (Fig. 1B). These data suggest that miR-145 expression is downregulated in GCs but is sustained or increased in scirrhous type GC.

Association between miR-145 expression and clinicopathological characteristics. To evaluate the correlation between miR-145 expression and clinicopathological factors, miR-145 expression was examined in 71 FFPE GC tissue samples using qRT-PCR. In this sample set, miR-145 expression was also significantly higher in scirrhous type GC cases than in non-scirrhous type $\mathrm{GC}$ cases ( $\mathrm{P}=0.0373$; Fig. $2 \mathrm{~A}$ ). miR-145 expression was significantly associated with tumor stage $(\mathrm{P}=0.0156)$ and scirrhous type GC cases $(\mathrm{P}=0.0054$; Table I).

We also examined the relationship between survival and miR-145 expression in 71 GC patients. Kaplan-Meier analysis showed that high miR-145 expression in GC patients correlated
Table I. Relationship between miR-145 expression and clinicopathological characteristics in 71 patients with GC.

\begin{tabular}{lrrr}
\hline & \multicolumn{2}{c}{ miR-145 expression } & \\
\cline { 2 - 3 } & High (\%) & Low & P-value ${ }^{\mathrm{a}}$ \\
\hline Age (years) & & & \\
$<60$ & $16(59.3)$ & 11 & 0.2265 \\
$\geq 60$ & $19(43.2)$ & 25 & \\
Gender & & & \\
$\quad$ Male & $11(50.0)$ & 11 & 1.0000 \\
Female & $24(49.0)$ & 25 & \\
Stage & & & \\
I/II & $9(31.0)$ & 20 & 0.0156 \\
$\quad$ III/IV & $26(61.9)$ & 16 & \\
Histological classification & & & \\
$\quad$ Well differentiated & $12(38.7)$ & 19 & 0.1528 \\
Poorly differentiated & $23(57.5)$ & 17 & \\
$\quad$ Non-scirrhous & $18(37.5)$ & 30 & 0.0054 \\
$\quad$ Scirrhous & $17(73.9)$ & 6 & \\
\hline
\end{tabular}

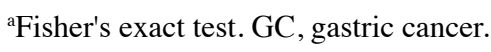


Table II. Univariate and multivariate analysis of factors influencing survival in 71 patients with GC.

\begin{tabular}{|c|c|c|c|c|}
\hline & \multicolumn{2}{|c|}{ Univariate analysis } & \multicolumn{2}{|c|}{ Multivariate analysis } \\
\hline & HR $(95 \%$ CI $)$ & P-value & HR $(95 \%$ CI $)$ & P-value \\
\hline \multicolumn{5}{|l|}{ Age (years) } \\
\hline$<60$ & 1 (Ref.) & & & \\
\hline$\geq 60$ & $1.14(0.55-2.48)$ & 0.7311 & & \\
\hline \multicolumn{5}{|l|}{ Gender } \\
\hline Female & 1 (Ref.) & & & \\
\hline Male & $0.75(0.36-1.65)$ & 0.4715 & & \\
\hline \multicolumn{5}{|l|}{ Stage } \\
\hline $\mathrm{I} / \mathrm{II}$ & 1 (Ref.) & & 1 (Ref.) & \\
\hline III/IV & $9.12(3.21-38.26)$ & $<0.0001$ & $8.39(2.77-36.28)$ & $<0.0001$ \\
\hline \multicolumn{5}{|l|}{ Histological type } \\
\hline Well differentiated & 1 (Ref.) & & & \\
\hline Poorly differentiated & $1.20(0.58-2.55)$ & 0.6273 & & \\
\hline Non-scirrhous & 1 (Ref.) & & & \\
\hline Scirrhous & $2.01(0.96-4.14)$ & 0.0606 & & \\
\hline \multicolumn{5}{|l|}{ Expression of miR-145 } \\
\hline Low & 1 (Ref.) & & 1 (Ref.) & \\
\hline High & $2.10(1.01-4.50)$ & 0.0457 & $1.41(0.67-3.06$ & 0.3595 \\
\hline
\end{tabular}

HR, hazard ratio; CI, confidence interval; GC, gastric cancer.

significantly with poorer cancer-specific mortality $(\mathrm{P}=0.0438$, log-rank test; Fig. 2B). When scirrhous type GC cases were compared with non-scirrhous type GC cases, miR-145 expression had no prognostic impact (data not shown). To determine the potential for miR-145 expression as a prognostic predictor in patients with $\mathrm{GC}$, univariate and multivariate Cox proportional hazards analyses were used to further evaluate the relationship between miR-145 expression and cancer-specific mortality (Table II). In the univariate analysis, high miR-145 expression and tumor stage were associated with poor survival rate $(\mathrm{P}=0.0457)$, and scirrhous type histology was also moderately associated with survival $(\mathrm{P}=0.0606)$. In the multivariate analysis, including miR-145 expression and tumor stage, miR-145 expression was not found to be an independent prognostic indicator of cancer-specific mortality $(\mathrm{P}=0.3595$; Table II).

miR-145 regulates $\alpha$-SMA expression in stromal fibroblasts of scirrhous type $G C$. It was previously reported that miR-145 is co-expressed as a cluster with miR-143 (15). We therefore investigated the correlation between miR-145 and miR-143 expression in 71 FFPE GC cases. As expected, expression levels of miR-143 and miR-145 were significantly correlated $(\mathrm{P}<0.0001 \mathrm{R}=0.5793$; Fig. 3A). Since we previously reported that miR-143 expression was localized in stromal fibroblasts in scirrhous type GC (13), we next performed qRT-PCR and confirmed the expression of miR-145 in GC cell lines and stromal fibroblasts of scirrhous type GC. Expression of miR-145 was detected in NFs and CaFs but not in GC cells, as shown in Fig. 3B. Furthermore, miR-145 expression was higher in $\mathrm{CaFs}$ than in NFs. These data suggest that in scirrhous type GC, miR-145 expression is localized in surrounding stromal fibroblasts but not in cancer cells.

Cancer-stromal interaction plays an important role in the progression of scirrhous type GC (3). We focused on the function of miR-145 in stromal fibroblasts. $\alpha$-SMA, a marker of myofibroblasts (32), was also expressed in CaFs and its expression was regulated by miR-145 (33). To determine whether miR-145 regulates $\alpha$-SMA expression in NFs and CaFs, we assessed the relationship between $\alpha$-SMA and miR-145. NF-38 and $\mathrm{CaF}-38$ were selected since they were established from the same patient with scirrhous type GC. We treated NF-38 and CaF-38 with pre-miR-145 or miR-145 inhibitor, and sequential changes in $\alpha$-SMA expression were examined by qRT-PCR and western blotting. Transfection of miR-145 precursor markedly increased $\alpha$-SMA expression, whereas transfection of miR-145 inhibitor sustained or suppressed $\alpha$-SMA expression (Fig. 3C-E). These data indicated that miR-145 positively regulates $\alpha$-SMA expression in stromal fibroblasts of scirrhous type GC.

TGF- $\beta$ regulates $\alpha$-SMA expression via miR-145. Scirrhous type GC secretes a larger amount of the active form of TGF- $\beta$ than non-scirrhous type GC (34), and TGF- $\beta$ has important pathological and biological roles in scirrhous type GC $(3,5,35,36)$. To investigate the effects of TGF- $\beta 1$ on miR-145 and $\alpha$-SMA expression, NF-38 and CaF-38 were treated with TGF- $\beta 1$, and their expression levels of miR-145 and $\alpha$-SMA were monitored by qRT-PCR. Treatment with TGF- $\beta 1$ resulted in strong induction of miR-145 and $\alpha$-SMA mRNA expression 

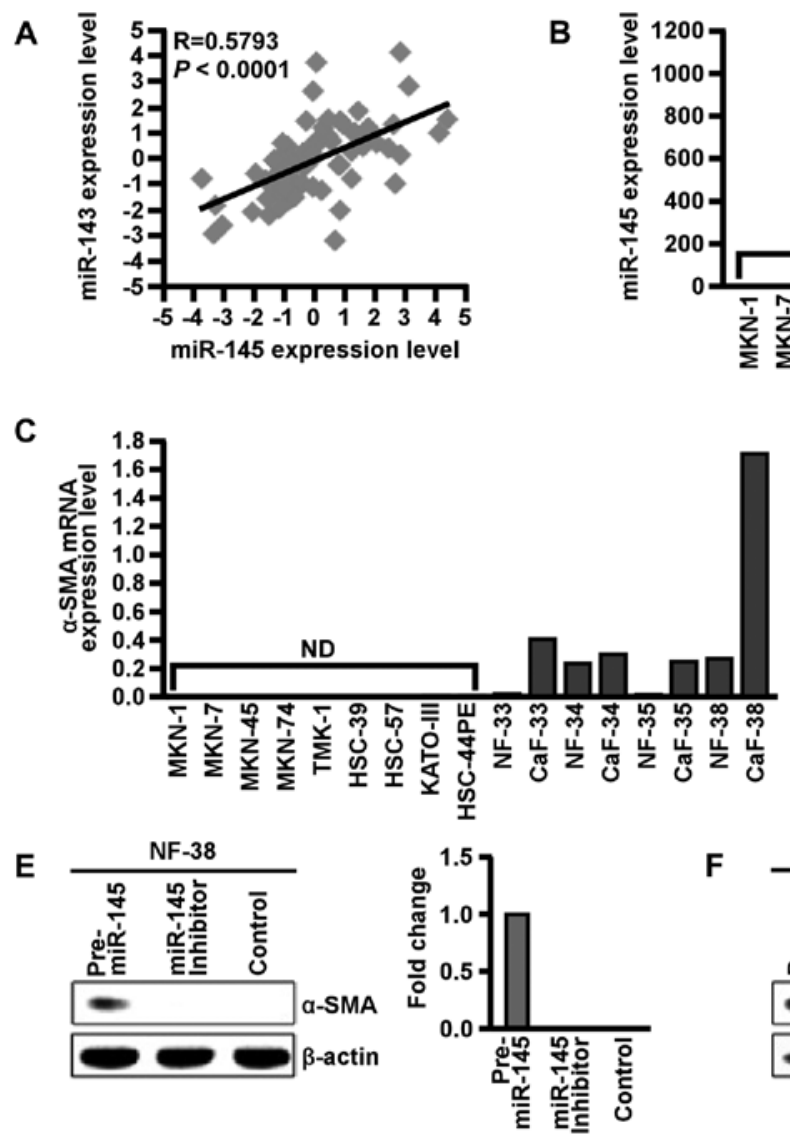
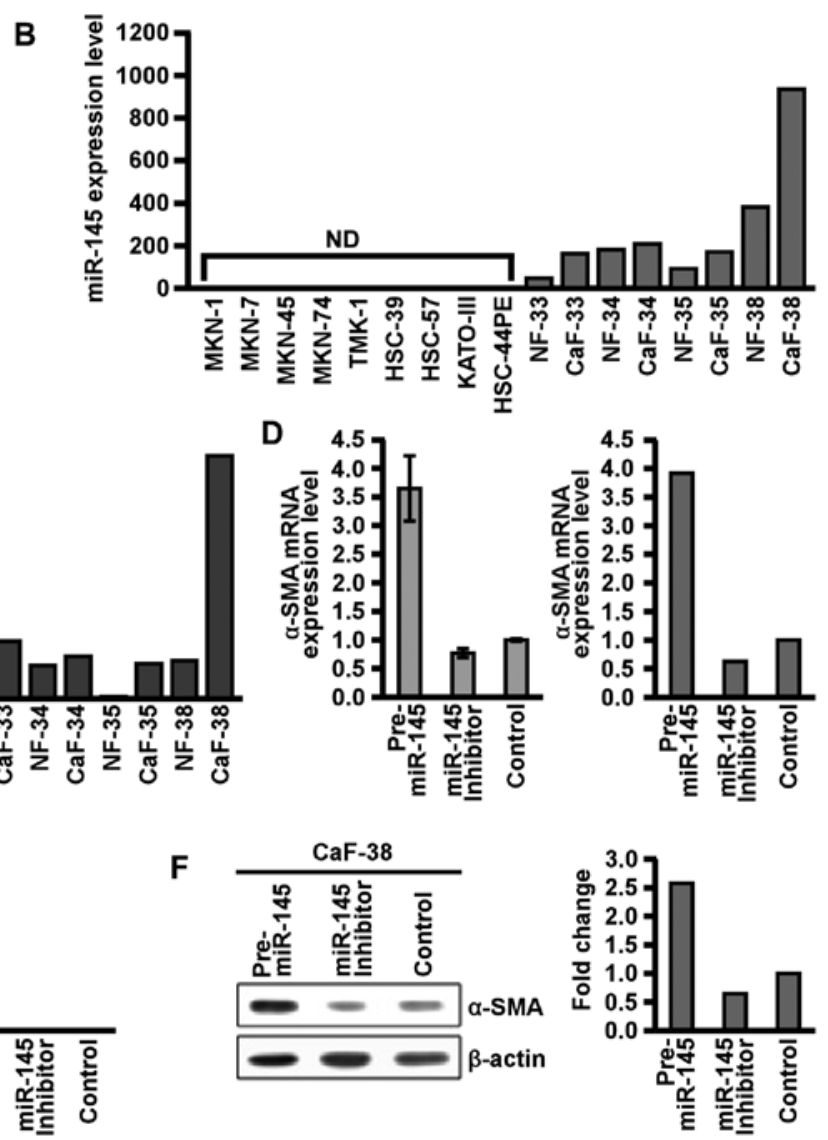

Figure 3. miR-145 target $\alpha$-smooth muscle actin ( $\alpha$-SMA) expression in fibroblasts of scirrhous type gastric cancer (GC). (A) The correlation between miR-145 and miR-143 expression in formalin-fixed paraffin-embedded gastric cancer (GC) tissue samples (n=71) was analyzed by quantitative RT-PCR (qRT-PCR). (B) miR-145 expression levels were evaluated in GC cell lines and fibroblasts. (C) $\alpha$-SMA mRNA expression levels were evaluated in GC and fibroblasts. (D) Expression levels of $\alpha$-SMA were measured by qRT-PCR in NF-38 and Caf-38 transfected with negative control miRNA or precursor miR-145 or miR-145 inhibitor. (E) Effects of negative control miRNA or precursor miR-145 or miR-145 inhibitor on $\alpha$-SMA expression in NF-38 and Caf-38 were measured by western blotting (left panel). Right panel shows densitometry analysis of western blot analyses. Results are means \pm SE of triplicate measurements. ND, not detected.
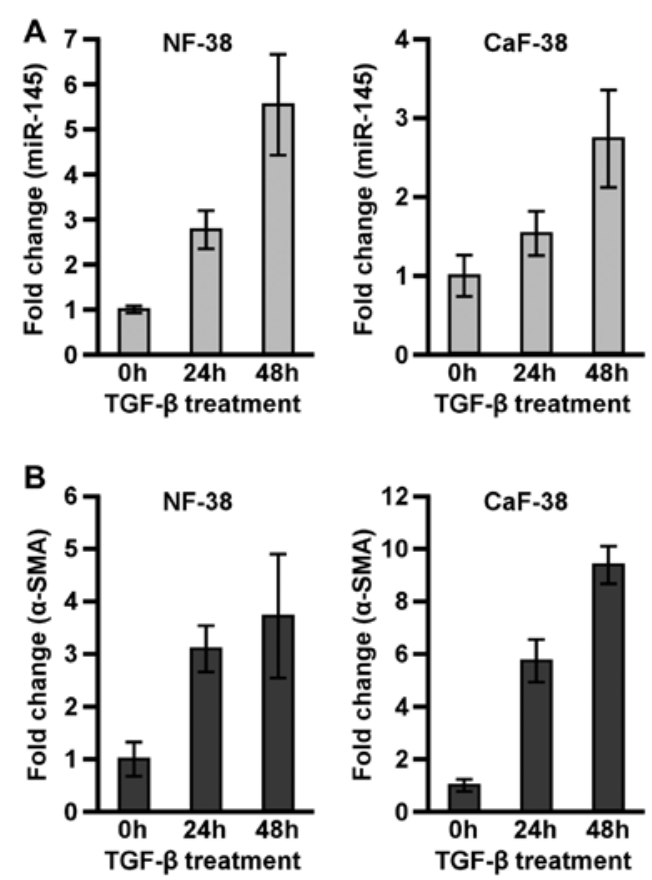

Figure 4. Effect of transforming growth factor- $\beta$ (TGF- $\beta$ ) on miR-145 and $\alpha$-SMA expression. Quantitative RT-PCR (qRT-PCR) analysis of (A) miR-145 and (B) $\alpha$-SMA mRNA in NF-38 and CaF-38 after the indicated times of TGF- $\beta 1$ treatment. (C) $\alpha$-SMA mRNA expression levels in NF-38 and CaF-38 in the absence or presence of TGF- $\beta 1$ with or without miR-145 inhibitor. Results are means \pm SE of triplicate measurements. 
within $48 \mathrm{~h}$ in both NF-38 and CaF-38 (Fig. 4A and B). However, the induction of $\alpha$-SMA mRNA by TGF- $\beta 1$ was significantly suppressed by pre-treatment with miR-145 inhibitor (Fig. 4C). These data indicate that miR-145 is deeply involved in the regulation of $\alpha$-SMA expression in $\mathrm{NF}$ and $\mathrm{CaF}$.

\section{Discussion}

In the present study, we reported that the expression of miR-145 was increased in scirrhous type GC tissues and was significantly associated with advanced cancer stage and poor clinical survival from GC. However, several lines of evidence suggest the miR-145 acts as a tumor suppressor gene, and its upregulation is correlated with better outcome (26-31). The apparent discrepancy between the data obtained from scirrhous type GC and other malignancies is worth consideration. It should be noted that these previous reports focused on cancer cells or normal stromal cells and not on peri-tumoral fibroblasts (26-31). We previously found that the expression of miR-143, co-regulated with miR-145, was localized in fibroblasts of scirrhous type $\mathrm{GC}$ and was associated with poor prognosis in the patients with GC (13). In the present study, we confirmed that miR-145 expression correlated strongly with miR-143 expression and was also detected in fibroblasts of scirrhous type GC. Collectively, the overexpression of miR-145 in cancer stroma may affect the progression of GC.

TGF- $\beta$ signaling plays an important role in promoting scirrhous type GC progression (3). TGF- $\beta$ also stimulates the proliferation of fibroblasts and regulates $\alpha$-SMA expression (3), which is a marker for activated fibroblasts and the contractility of fibroblasts $(32,33)$. The contractile force of fibroblasts is closely associated with TGF- $\beta$ activation and the viability of fibroblasts (33). Moreover, such fibroblasts expressing $\alpha$-SMA contributed to the proliferation and motility of scirrhous type GC cells (20). Here, we showed the expression of miR-145 and $\alpha$-SMA in NFs and CaFs was induced by TGF- $\beta$ treatment, and miR-145 was involved in the induction of $\alpha$-SMA expression by TGF- $\beta$. These data suggest that miR-145 in peri-tumoral fibroblasts may support the progression of scirrhous type GC through the regulation of $\alpha$-SMA expression.

It was reported that $\alpha$-SMA expression was regulated by miR-145 through inhibition of Krüppel-like factor 4 (KLF4) gene translation (33). Thus, it could be hypothesized that miR-145 also targets the translation of KLF4 and indirectly regulates $\alpha$-SMA expression in fibroblasts of scirrhous type GC. We performed qRT-PCR and western blot analysis of KLF4 to determine whether miR-145 regulates KLF4 gene expression. However, we failed to detect the inhibition of KLF4 expression by miR-145 in NF-38 and CaF-38 (data not shown). The effects of KLF4 and other target genes of miR-145 on $\alpha$-SMA regulation were not investigated in the present study. Further investigations should be performed to clarify the underlying mechanism of $\alpha$-SMA regulation by miR-145 in NFs and CaFs of scirrhous type GC.

In conclusion, miR-145 expression in stromal fibroblasts of scirrhous type GC may be involved in cancer progression and lead to poor clinical outcome. Full elucidation of the molecular mechanisms of miR-145 in stromal fibroblasts surrounding cancer cells may improve our understanding of tumor progression in scirrhous type GC.

\section{Acknowledgements}

The authors thank Mr. Shinichi Norimura for his technical assistance. This study was carried out with the kind cooperation of the Research Center for Molecular Medicine, Faculty of Medicine, Hiroshima University. We thank the Analysis Center of Life Science, Hiroshima University, for the use of their facilities. This study was supported by Grants-in-Aid for Research from the Ministry of Education, Culture, Science, Sports, and Technology of Japan, and, in part, by a Grantin-Aid for the Third Comprehensive 10-Year Strategy for Cancer Control and for Cancer Research from the Ministry of Health, Labour and Welfare of Japan, and for The National Institute of Biomedical Innovation (Program for Promotion of Fundamental Studies in Health Sciences). This study was also supported in part by a Research Fellowship of the Japan Society for the Promotion of Science and the National Cancer Center Research and Development Fund (23-A-9).

\section{References}

1. Otsuji E, Kuriu Y, Okamoto K, et al: Outcome of surgical treatment for patients with scirrhous carcinoma of the stomach. Am J Surg 188: 327-332, 2004.

2. Ikeguchi M, Miyake T, Matsunaga T, et al: Recent results of therapy for scirrhous gastric cancer. Surg Today 39: 290-294, 2009.

3. Yashiro M and Hirakawa K: Cancer-stromal interactions in scirrhous gastric carcinoma. Cancer Microenviron 3: 127-135, 2010.

4. Yamamoto M, Sumiyoshi H, Nakagami K, Taniyama K and Tahara E: Distribution of collagen types I and III and basal lamina in human gastric carcinoma: an immunohistochemical and electron microscopic study. Virchows Arch A Pathol Anat Histopathol 403: 313-322, 1984.

5. Yoshida K, Yokozaki H, Niimoto M, Ito $H$, Ito $M$ and Tahara E: Expression of TGF- $\beta$ and procollagen type I and type III in human gastric carcinomas. Int J Cancer 44: 394-398, 1989.

6. Jain RK: Barriers to drug delivery in solid tumors. Sci Am 271: 58-65, 1994.

7. Heldin $\mathrm{CH}$, Rubin K, Pietras K and Ostman A: High interstitial fluid pressure - an obstacle in cancer therapy. Nat Rev Cancer 4: 806-813, 2004

8. NakajimaTE, Yanagihara K, Takigahira M, et al: Antitumor effect of SN-38-releasing polymeric micelles, NK012, on spontaneous peritoneal metastases from orthotopic gastric cancer in mice compared with irinotecan. Cancer Res 68: 9318-9322, 2008.

9. Worthley DL, Giraud AS and Wang TC: The extracellular matrix in digestive cancer. Cancer Microenviron 3: 177-185, 2010.

10. Bartel DP: MicroRNAs: genomics, biogenesis, mechanism, and function. Cell 116: 281-297, 2004.

11. Ambros V: The functions of animal microRNAs. Nature 431: 350-355, 2004.

12. Calin GA and Croce CM: MicroRNA signatures in human cancers. Nat Rev Cancer 6: 857-866, 2006.

13. Naito Y, Sakamoto N, Oue N, et al: MicroRNA-143 regulates collagen type III expression in stromal fibroblasts of scirrhous type gastric cancer. Cancer Sci 105: 228-235, 2014.

14. Cordes KR, Sheehy NT, White MP, et al: miR-145 and miR-143 regulate smooth muscle cell fate and plasticity. Nature 460: 705-710, 2009.

15. Iio A, Nakagawa Y, Hirata I, Naoe T and Akao Y: Identification of non-coding RNAs embracing microRNA-143/145 cluster. Mol Cancer 9: 136, 2010.

16. Long X and Miano JM: Transforming growth factor- $\beta 1$ (TGF- $\beta 1$ ) utilized distinct pathways for the transcriptional activation of microRNA 143/145 in human coronary artery smooth muscle cells. J Biol Chem 286: 30119-30129, 2011.

17. Ochiai A, Yasui W, Kameda T, Takanashi A, Takekura N and Tahara E: The effect of phorbol esters on cell growth and epidermal growth factor receptor modulation in a human gastric carcinoma cell line TMK-1. Hiroshima J Med Sci 38: 191-195, 1989. 
18. Yanagihara K, Seyama T, Tsumuraya M, Kamada N and Yokoro K: Establishment and characterization of human signet ring cell gastric carcinoma cell lines with amplification of the c-myc oncogene. Cancer Res 51: 381-386, 1991.

19. Yanagihara K, Tanaka H, Takigahira M, et al: Establishment of two cell lines from human gastric scirrhous carcinoma that possess the potential to metastasize spontaneously in nude mice. Cancer Sci 95: 575-582, 2004.

20. Fuyuhiro Y, Yashiro M, Noda S, et al: Cancer-associated orthotopic myofibroblasts stimulates the motility of gastric carcinoma cells. Cancer Sci 103: 797-805, 2012.

21. Naito Y, Oue N, Hinoi T, et al: Reg IV is a direct target of intestinal transcriptional factor CDX2 in gastric cancer. PLoS One 7: e47545, 2012.

22. Kondo T, Oue N, Yoshida K, et al: Expression of POT1 is associated with tumor stage and telomere length in gastric carcinoma. Cancer Res 64: 523-529, 2004.

23. Shinmei S, Sakamoto N, Goto K, et al: MicroRNA-155 is a predictive marker for survival in patients with clear cell renal cell carcinoma. Int J Urol 20: 468-477, 2013.

24. Yasui W, Ayhan A, Kitadai Y, et al: Increased expression of $\mathrm{p} 34 \mathrm{cdc} 2$ and its kinase activity in human gastric and colonic carcinomas. Int J Cancer 53: 36-41, 1993.

25. Ueda T, Volinia S, Okumura H, et al: Relation between microRNA expression and progression and prognosis of gastric cancer: a microRNA expression analysis. Lancet Oncol 11: 136-146, 2010.

26. Liu L, Chen Q, Lai R, et al: Elevated expression of mature miR-21 and miR-155 in cancerous gastric tissues from Chinese patients with gastric cancer. J Biomed Res 24: 187-197, 2010.

27. Gao P, Xing AX, Zhou GY, et al: The molecular mechanism of microRNA-145 to suppress invasion-metastasis cascade in gastric cancer. Oncogene 32: 491-501, 2013.
28. Zheng L, Pu J, Qi T, et al: miRNA-145 targets v-ets erythroblastosis virus E26 oncogene homolog 1 to suppress the invasion, metastasis, and angiogenesis of gastric cancer cells. Mol Cancer Res 11: 182-193, 2013.

29. Ostenfeid MS, Bramsen JB, Lamy P, et al: miR-145 induces caspase-dependent and -independent cell death in urothelial cancer cell lines with targeting of an expression signature present in Ta bladder tumors. Oncogene 29: 1073-1084, 2010.

30. Hamano R, Miyata H, Yamasaki M, et al: Overexpression of miR-200c induces chemoresistance in esophageal cancers mediated through activation of the akt signaling pathway. Clin Cancer Res 17: 3029-3038, 2011.

31. Villadsen SB, Bramsen JB, Ostenfeld MS, et al: The miR-143/-145 cluster regulates plasminogen activator inhibitor-1 in bladder cancer. Br J Cancer 106: 366-374, 2012.

32. Kalluri R and Zeisberg M: Fibroblasts in cancer. Nat Rev Cancer 6: 392-401, 2006.

33. Yang S, Cui H, Xie N, et al: miR-145 regulates myofibroblast differentiation and lung fibrosis. FASEB J 27: 2382-2391, 2013.

34. Mahara K, Kato J, Terui T, et al: Transforming growth factor beta 1 secreted from scirrhous gastric cancer cells is associated with excess collagen deposition in the tissue. Br J Cancer 69: 777-783, 1994.

35. Kawajiri H, Yashiro M, Shinto O, et al: A novel transforming growth factor $\beta$ receptor kinase inhibitor, A-77, prevents the peritoneal dissemination of scirrhous gastric carcinoma. Clin Cancer Res 14: 2850-2860, 2008.

36. Shinto O, Yashiro M, Kawajiri $\mathrm{H}$, et al: Inhibitory effect of a $\mathrm{TGF} \beta$ receptor type-I inhibitor, Ki26894, on invasiveness of scirrhous gastric cancer cells. Br J Cancer 102: 844-851, 2010. 